\title{
A TEXTUALIZAÇÃO DE CORPOS DOENTES ATRAVÉS DE IMAGENS: uma das lições da UTI contemporânea*
}

Mara Ambrosina de Oliveira Vargas** Dagmar Estermann Meyer ${ }^{\star \star \star}$

\section{Resumo}

Este artigo é parte de uma dissertação em que se discutiu o que chamamos de 'processo de ciborguização da enfermeira' no contexto da terapia intensiva. Para isso, buscamos apoio na teorização cultural e no trabalho de Donna Haraway e seu entendimento de ciborgue. Escolhemos como corpus de análise alguns manuais e protocolos assistenciais. Utilizamos a abordagem metodológica da análise cultural tal como esta vem sendo desenvolvida pelos Estudos Culturais que se aproximam do Pósestruturalismo, para descrever e analisar a produção de imagens de corpos doentes e sua decodificação, através de um complexo sistema de monitoramento no qual se conectam, de diferentes modos e com diferentes efeitos, corpos doentes, máquinas e corpos de profissionais da enfermagem. Concluimos que é necessário e pertinente visualizar e problematizar toda essa rede de relações como instâncias de produção e disseminação de sentidos sobre o corpo, a vida e o cuidar em enfermagem.

Descritores: estudos culturais e educação corpo/máquina; enfermagem em terapia intensiva; tecnologias em enfermagem

\section{Abstract}

This paper belongs to a dissertation in which, what we have call "nursing worker cyborgizing" in intensive therapy is discussed. In order to carry out this discussion we based our work on cultural theorizing, as well as on Donna Haraway understanding of cyborg. For the corpses analysis manuals and assistance protocols were used. The methodological approach used in this work is the cultural analysis, as it has been used in the Poststructuralist Cultural Studies, in order to describe and analyze the production of images of sick bodies and its decoding process through a complex monitoring system in which sick bodies, machines and nursing practitioners, connect in different ways and effects. We have concluded that it is useful and relevant to consider and discuss these instances of production and diffusion of meanings attributed to the body, life, and the Nursing care.

Descriptors: Cultural studies and education; body/machine; Intensive Therapy in Nursing; technologies in nursing.

Title: Sick bodies textualized through images: what contemporary intensive therapy unit can teach us

\section{Resumen}

Este artículo es parte de una disertación, en la cual se ha planteado lo que hemos llamado "el proceso de ciborquización de la enfermera" en el contexto de la terapia intensiva. Hemos buscado apoyo en la teorización cultural y en el trabajo de Donna Haraway y lo que entiende por ciborgue . El corpus de análisis son algunos manuales y protocolos asistenciales. El abordaje metodológico es el del análisis cultural, tal como se viene desarrollando en los Estudios Culturales que se aproximan al Posestructuralismo, para describir y analizar la producción de imágenes de cuerpos enfermos y su decodificación, a través de un complejo sistema de monitoramiento en el cual se conectan, de diferentes modos y efectos, cuerpos enfermos, máquinas y cuerpos de profesionales de enfermería. Se concluye lo necesario y pertinente que es visualizar $y$ problematizar esa red de relaciones como instancias de producción y diseminación de sentidos sobre el cuerpo, la vida y el cuidado en enfermería.

Descriptores: Estudios culturales y educación; cuerpo/máquina; enfermería en terapia intensiva; tecnologías en enfermería

Título: La textualización de cuerpos enfermos a través de imágenes: una de las lecciones de la uti contemporánea

\section{Introdução}

Este artigo é parte de uma dissertação em que se discutiu o que chamamos de 'processo de ciborguização da enfermeira' no contexto da unidade de terapia intensiva. Para isso, buscamos apoio na teorização cultural e no trabalho de autores e autoras que têm problematizado a noção de corpo e de sujeito na pósmodernidade a partir dos pressupostos teóricos do pósestruturalismo. Ao seguir tais pressupostos, entendeu-se que tanto o humano quanto a máquina são significados culturalmente e que tais significados têm sido produzidos dentro de práticas discursivas específicas. Desde essa perspectiva, procuramos evidenciar, dentre as lições decorrentes do uso intensivo da tecnologia no contexto de saúde, de modo geral, e na UTI, em especial, uma problemática particular, qual seja, a da conversão dos/as profissionais em híbridos humanos-máquinas.

Entre os/as autores /as utilizados, indicamos os estudos de Donna Haraway ${ }^{(1,2,3)}$ e seu entendimento de ciborgue - uma idéia produtiva que possibilita explorar a ciborguização da cultura contemporânea e suas implicações para a enfermagem em terapia intensiva. O confronto com a figura do ciborgue, um construto que evidencia a ambíguidade das fronteiras onde as diferenças entre máquinas e humanos são definidas e que, ao mesmo tempo, coloca em xeque um a priori de "naturalidade", nos permite sustentar a noção de que a interface a partir da qual se define o que vem a ser considerado "natural" e "nãonatural" está inserida em práticas culturais e sociais complexas e, em última análise, contingentes. Com o conceito de ciborgue buscamos operar, no contexto da problematizaçãodesenvolvida no estudo, no próprio limiar entre as fronteiras do que tem sido afirmado e reafirmado como sendo saúde, doença, vida, morte, humano e tecnologia, natural e artificial, orgânico e inorgânico.

Para isso escolhemos como corpus de análise, dentre vários materiais pedagógicos disponibilizados para a equipe de enfermagem em terapia intensiva, alguns manuais e protocolos assistenciais. A partir do exame desses manuais e protocolos assistenciais, procuramos argumentar que, mesmo quando estes operam com algumas polaridades e posicionamentos bem delimitados por pressupostos científicos, o fazem com uma certa ambigüidade quando se trata de abordar ou descrever a relação enfermeira-máquina. Cientes de que tal ambigüidade não é explícita, o exercício que fizemos foi o de, justamente, pretender dar-lhe visibilidade. Sob os pressupostos da análise cultural, os manuais e protocolos assistenciais funcionaram como textos culturais que nos permitiram discutir mudanças das/nas práticas da enfermeira intensivista mediante sua imbricação com os equipamentos da tecnobiomedicina, da bioeletrônica e da informática.

Este artigo, em particular, aborda um dos acontecimentos

* Este trabalho é parte da dissertação de mestrado de Vargas, intitulada Corpus ex machina: a ciborguização da enfermeira no contexto da terapia intensiva, Pós-Graduação em Educação, da Universidade Federal do Rio Grande do Sul, dezembro 2002.

** Mestre em Educação. Professora Adjunta na Enfermagem da UNISINOS, Enfermeira Assistencial do Centro de Tratamento Intensivo Adulto do Hospital de Clínicas de Porto Alegre/UFRGS.

*** Doutora em Educação. Professora Adjunta na Faculdade de Educação da UFRGS, atual coordenadora do grupo de Estudos de Educação e Relações de Gênero, na mesma instituição.

E-mail dos autores: maraav@terra.com.br e esterman.ez@brturbo.com. 
analisados nessa pesquisa mais ampla, o qual, em nossa opinião, sintetiza significados importantes produzidos pela articulação humano-máquina, na terapia intensiva, na contemporaneidade, a saber: a produção de imagens de corpos doentes e sua decodificação, através de um complexo sistema de monitoramento no qual se conectam, de diferentes modos e com diferentes efeitos, corpos doentes, máquinas e corpos de profissionais da enfermagem.

\section{Imagens que textualizam corpos doentes}

Descartes tem sido considerado o principal mentor da separação entre o corpo e a mente na Modernidade. Sob a vigência desse pressuposto, já no século XVIII, falava-se em doenças da mente e doenças do corpo. O hospital, desde então, tornou-se o grande centro dos estudos das doenças do corpo e, nesse lugar, o corpo foi constituído e significado pela linguagem enquanto objeto do saber. A doença, por sua vez, enquanto linguagem, significou o corpo como um corpo doente.

Atualmente, a UTI, como um cenário caracterizado, entre outras coisas, pela utilização de diversos equipamentos, significa o corpo como corpo gravemente doente, exatamente, porque ele se encontra acoplado à máquina. A máquina hibridizada com a enfermeira intensivista transforma o corpo gravemente doente, através de distintas linguagens imagéticas, em texto. Essas imagens de corpos doentes, geradas pelo acoplamento de um paciente e/ou uma enfermeira às mais diversas máquinas na UTI, reconfiguram estes corpos como textos que devem ser decifrados ou lidos pela enfermeira intensivista, e não como algo a ser contemplado. Nessa perspectiva, essas imagens passam a ser vistas como uma construção e como discurso. Assim, o que nós vemos é o que aprendemos a ver. Aprendemos, pois, a ver e a interpretar o que vemos de muitas formas diferentes. $\mathrm{E}$ o que aqui nos interessa é o modo como olhamos essas imagens ou, ainda, o modo como traduzimos o que olhamos, mediadas por tais imagens. Opera-se, aí, no mínimo, um duplo aprendizado: aprendemos a olhar, conhecer e definir corpos com essas imagens e aprendemos a operar com eles, de determinado modo, a partir dessas imagens. Tomamos decisões terapêuticas e do cuidar em enfermagem apoiadas no conhecimento extraído dessas imagens.

A questão do olhar tem estado no centro da análise cultural. Visão, observação e registro são "inseparáveis nas estratégias de inscrição utilizadas pela ciência"(4:60). Assim como há uma conexão necessária entre processos de significação e poder, há também uma conexão "correspondente entre visão e poder. Por seu caráter ativo, a visão é, de todos os sentidos, talvez aquele que mais expresse a presença e a eficácia do poder"(4:60).

Visualizar os corpos já era uma prática importante no século XVIII e início do século XIX com a intensificação da relação da ciência com a medicina. A obra Nascimento da Clínica ${ }^{(5)}$, propôs-se a discutir os modos pelos quais o corpo foi tomado como alvo e objeto de saber, e isso viabilizou-se através da possibilidade de desvelar, historicamente, a medicina como ciência justamente porque estava nascendo, através da experiência clínica, uma nova forma de lidar com a doença. Deste modo, a experiência clínica armava-se para explorar um novo espaço: o espaço tangível do corpo doente sob o olhar médico. Percebido sob esse olhar, o corpo doente era falado, classificado e organizado em tipologias nosológicas, as quais não existiriam em essência, mas como doença de um corpo específico, concreto. A linguagem médica era vista em perfeita articulação com seu objeto, o corpo doente percebido pelo olhar daquele que examinava ${ }^{(5)}$. A ciência denominou esse jeito de olhar de exame físico ou de anamnese clínica, olhar direcionado por informações subjetivas ou por características disseminadas nas superfícies dos corpos-pacientes.

Com o desenvolvimento da anatomia patológica por
Morgagni em 1760, a análise clínica passa a ser realizada no interior do próprio corpo doente, ou seja, busca-se desvelar na profundidade das coisas o que estava disseminado nas superfícies dos corpos. A anatomia patológica fundamentouse, principalmente, no princípio de que as lesões explicavam os sintomas objetivos e subjetivos. Nesse sentido, o olhar do pesquisador começa a descrever a intimidade do corpo humano a partir da abertura sistemática de cadáveres e, com essa prática, a fronteira onde a doença era lida somente pelo testemunho mórbido ou pelos sinais visíveis na superfície do corpo-paciente foi ultrapassada. Sendo assim, o médico procura a essência da lesão em sua organização histológica, já que, munido de elementos nosológicos, ele a re/conhece por que a vê.

Em suma, com a perspectiva positivista, a doença desprende-se da metafísica, e é na contramão desse pressuposto que se apresenta o caráter positivista da exploração do corpo - um corpo iluminado, que se deixa ver, minuciosamente explicado e subjugado às leis que justificam os dados recolhidos através de sua observação e que legitimam os processos de detecção de doenças ou causas mórbidas através da visibilidade da morte. A doença, a vida e a morte deixavam de ser um mistério existencial e tornavam-se um problema técnico.

A medicina, em plena emergência do século $X X I$, ainda estabelece uma relação da doença com a sintomatologia subjetiva do indivíduo e trata os dados objetivos como sinais. No entanto, a morte deixou, há muito, de ser a única ou a mais importante fonte de conhecimentos acerca dos corpos. A esse respeito mesmo entendendo que essa medicina atual ainda está centrada no Positivismo é afirmado que a concepção atual de lei apresenta alguma variação.

Essa lei não é mais aquela que se confirma com a totalidade dos casos, mas aquela de perspectiva probabilística e feita sob certas condições, já que o arcabouço tecnológico se mostra mais sensível às variações do real(6:25).

Convém lembrar que a informação gerada a partir desse aparato tecnobiomédico é, na maioria das vezes, numerizada. Assim, mesmo que no contexto de intensivismo operemos muito com a linguagem da biologia, é, todavia, a linguagem matemática, cujo instrumento é o número, que aí impera. Nesta perspectiva existe informação quando a mensagem a ser decodificada não carrega mais nenhum traço de seu sentido. Se o corpo-paciente já não pode dizer de si e se a enfermeira intensivista também já não pode dizer do que vê sem a mediação da máquina, poder-se-ia argumentar que a máquina diz aquilo que paciente e profissional não disseram. A relação, nesse caso, não é mais de ver e re/conhecer, mas de substituir a presença do corpo concreto, escrevendo-o em números, delimitando as suas medidas, os seus valores. A enfermeira, por sua vez, traduz essa linguagem matemática em um texto que pode ser lido como substitutivo das coisas do corpopaciente.

Seria, então, possível dizer que, ao textualizar o corpo de determinados modos, a máquina o constitui com outros sentidos? Se respondermos positivamente a esta questão, podemos, então, operar com o pressuposto de que é pela possibilidade de olhar o corpo pela máquina que o mesmo é configurado de outra forma, não mais idêntica a esse corpopaciente; é com e através da máquina que ele se transforma em outro texto, com outros sentidos em relação a alguma percepção concreta desse mesmo corpo; um texto que é legível, com determinados efeitos, nesse campo profissional:

Devido à utilização rotineira da monitorização cardíaca, as arritmias cardíacas são freqüentemente identificadas no paciente internado em centro de terapia intensiva ${ }^{(8: 86)}$. 
e anotar todos os parâmetros das pressões: $P A D$ (pressão do átrio direito), PAP (pressão da artéria pulmonar), POAP (pressão de oclusão da artéria pulmonar) e três medições de DC.(débito cardíaco) Para qualquer valor que não corresponda à clínica e tratamento instituído, tomar providências junto com os médicos, para a correção imediata. [...] Observar a morfologia das curvas, identificando a posição ideal do catéter. [...] Zerar o transdutor a cada oito horas. [...]Observar presença de ar no sistema. Checar todas

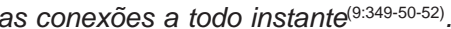

As medidas das pressões sangüíneas (PAD, PAP e POAP) e da quantidade de volume de sangue injetado pelo coração por minuto (DC) e o controle de uma possível alteração no ritmo cardíaco, tal como são explicitadas nessas citações, constituem valores capazes de traduzir alguma anormalidade ou normalidade do corpo-paciente, justamente porque é o discurso do intensivismo que atribui sentidos a elas. Dessa maneira, fora da UTI e sem a leitura feita pelos/as profissionais que lá trabalham quando identificam e relacionam os números, as curvas, as ondas, os gráficos, os traçados e as imagens do visoscópio com o corpo-paciente, tais medidas seriam destituídas de qualquer sentido, ou, no mínimo, produziriam outros possíveis sentidos.

Em função disso, as UTIs têm-se constituído como um locus onde um conjunto renovado de saberes e de aparatos tecnológicos torna possível esse acesso rápido às variações do que tem sido definido como real. A transformação das informações acerca dos dados fisiológicos e de relatos subjetivos em estimativas objetivas faz com que a evidência de alteração clínica consiga ser avaliada antes mesmo de o indivíduo percebê-la:

Em cuidados intensivos, você precisa da monitorização que é sempre predizível. Porque seus pacientes não são predizíveis ${ }^{(10)}$.

Uma consulta ao dicionário informa que monitorizar significa prevenir, avisar, avaliar e agir. No caso das UTIs, a monitorização visa à medição freqüente e repetida das variáveis fisiológicas e constitui-se na base da estruturação de uma unidade de tratamento intensivo. Não há terapia intensiva sem monitorização intensiva. A monitorização hemodinâmica invasiva e não-invasiva, por sua vez, é utilizada para o diagnóstico, para a terapêutica e, até mesmo, para fazer um prognóstico com os dados obtidos. Sua finalidade é fazer com que o/a profissional reconheça e avalie possíveis problemas, em tempo hábil, com o objetivo de estabelecer uma terapia adequada imediata ${ }^{(11)}$.

Passo 2. Certifique-se de que o Servidor de Medidas está conectado ao monitor. Passo 3. Se o paciente já está ligado ao Servidor de Medidas, deve-se poder visualizar as ondas e os valores numéricos configurados na tela. Caso contrário: coloque no paciente os eletrodos sondas ou transdutores, ou insira os cateteres de pressão necessários para monitorização. Conecte os eletrodos, sondas e transdutores ao Servidor de Medidas. Treine algumas vezes para aprender a diferença de pressão entre os dois níveis - pode-se treinar primeiro realçando e depois selecionando a Tecla de Função 'Tendências' (pressione a tecla azul Tela Principal para voltar à tela principal de monitorização) ${ }^{(12: 37)}$

Este excerto indica que os diversos tubos, as linhas, os transdutores e os cateteres devem estar conectados ao/à paciente e, ao mesmo tempo, aos computadores. O que inferimos, através dessa indicação, é que estaríamos, com essas possíveis conexões dos equipamentos com o corpo-paciente, lidando com diversas câmeras que, por sua vez, estariam filmando o corpo-paciente. São diferentes filmagens, de diversos ângulos, que nos são mostradas concomitantemente. Verdadeiro espetáculo do olhar: corpo-paciente, construído e reconstruído como objeto concreto do discurso da tecnobiomedicina. Tais sentidos capturados do corpo, no entanto, não estão dados nas imagens geradas pelos equipamentos. Eles só se concretizam quando passam a ser lidos de determinado modo pelos/as profissionais subjetivados/as por esse discurso. Esses sujeitos-profissionais, conectados aos computadores utilizados nas mais diversas máquinas da tecnobiomedicina, vivenciam, então, novas maneiras de ver o corpo. Não se trata de ver melhor ou pior, mas de ver de outro modo.

Portanto, pode-se considerar que aqueles/as que trabalham em um ambiente complexo e carregado de monitoramento conseguem ver os/as pacientes de diferentes perspectivas, em muitos locais de seu corpo, porque os computadores, através do processo de decodificação dos sinais, transformam o corpo em informação. Ou, também, é possível observar que esses/as profissionais visualizam a mesma imagem repetidas vezes, já que o sistema de monitoramento armazena informações - tem memória -, possibilitando a leitura e releitura dos corpos-pacientes. Para além disso, é possível dizer que uma enfermeira intensivista, diante do monitor microprocessado, multiplica todo um complexo de informações sobre o corpo-paciente e cria uma noção de conjunto inacessível ao/à profissional que utiliza apenas a sua capacidade de observar através dos sentidos, e, no contexto desta investigação, tudo isso concorre para demonstrar um processo de ciborguização da enfermeira intensivista.

No entanto, a discussão que desejamos introduzir, aqui, aponta para o aspecto do quanto devemos nos tornar responsáveis pelo que aprendemos a ver. Nesta direção, desde essa perspectiva de análise, entendemos que as delimitações de algumas polaridades são teorizadas muito mais como movimentos de poder do que movimentos em direção a verdade. Ou seja, ressaltamos o caráter dinâmico das tecnologias médicas como instrumentos para a imposição de novos significados e o que tem sido validado em cada época para traduzir a realidade do corpo doente ${ }^{(1-3)}$. Essa tradução da realidade do corpo doente, mesmo que envolvida em um processo contínuo de diferenciação, em dado momento é fixada através de alguma/s polaridade/s. Isto é, na medida em que entram em jogo outras opções tecnológicas, algumas polaridades são secundarizadas, outras são invertidas (o termo que em um primeiro momento é privilegiado, em outro momento, interessadamente é deslocado) e poucas são até abandonadas. Mas, ao nosso ver, para além de examinar as relações entre os termos que constituem uma determinada dicotomia, esse próprio caráter dinâmico do que conta como verdade também entra em um processo de diferimento. $\mathrm{O}$ modo de abordar a monitorização hemodinâmica nas edições de 90 , 93 e 2001 do manual Rotinas em Terapia Intensiva permite discutir melhor esse processo:

A monitorização hemodinâmica é mais uma arma no manejo do paciente gravemente enfermo, e como tal deve ser adequadamente utilizada. Nunca deve ser subvalorizada a avaliação subjetiva do paciente, que a despeito de toda a moderna tecnologia ainda persiste como o maior e melhor método de avaliação. Dados erroneamente coletados ou interpretados podem conduzir a caminhos desastrosos. Assim, é importante avaliação meticulosa de cada valor obtido durante a monitorização. Finalmente, um conceito que deve estar sempre presente é o de que monitorar não é tratar, mas sim discernir a orientação a ser tomada (13:55)

Os catéteres de Swan-Ganz [ ] representam um grande auxílio na coleta de informações do paciente gravemente enfermo, na medida em que fornecem um meio fácil, seguro e contínuo de verificar pressões de artéria pulmonar e de encunhamento capilar pulmonar [...] e débito cardíaco ${ }^{(14: 307)}$.

As controvérsias quanto às indicações do uso do 
cateterismo cardíaco à beira do leito se devem ao fato de os estudos clínicos não terem demonstrado a diferença no prognóstico final dos pacientes que o utilizam $^{(15: 47)}$

Em um primeiro momento, em 1990, o procedimento da monitorização hemodinâmica à beira de leito, recém inserido no contexto da terapia intensiva, mostrava-se como algo promissor e ainda percebido como algo a ser melhorado, conhecido e explorado pelos profissionais que o utilizariam. Isto é, mesmo que a inserção do cateter de Swan-Ganz fosse entendida como um importante avanço, tal procedimento era associado a outras maneiras de observar e obter dados da doença de um determinado paciente. Naquele momento, a dicotomia que ancorava a argumentação desenvolvida era, nada mais, nada menos, do que a relação dados subjetivos/dados objetivos. Aí, importava como os sintomas referidos pelos pacientes eram avaliados na sua interface com a máquina e como os sintomas detectados pelo humano, através da máquina, eram avaliados na sua interface com o humano. Já em 1993, pela intensificação da utilização desse procedimento, enfatizavam-se suas vantagens sobre os outros procedimentos possíveis de serem realizados à beira do leito. A polaridade inverteu-se em 1993 para operar a validação e confiabilidade dos dados objetivos em detrimento dos dados subjetivos. Subjetividade versus objetividade, objetividade versus subjetividade, o sujeito que investiga o corpo é subjetivado em sua relação com a máquina; o corpo como objeto de investigação é objetivado em sua relação com a máquina. Desconstruir essa polaridade é torná-los, ambos, sujeito e objeto de (e dentro de) um mesmo jogo de significação. Humano e máquina são pensados como sujeito e objeto do conhecimento, em uma relação paralela. Nessa relação paralela, corpos e máquinas não jazem inertes prontos para serem lidos. Assim, o/a paciente fornecendo informações ao/à profissional acerca de seus sintomas e a máquina fornecendo informação à/ao profissional, através de medições e estimativas, são relações que estão inseridas em um mesmo conhecimento específico, constituído em uma relação social de conversa carregada de poder ${ }^{(2)}$.

Porém, em 2001, pelo aprimoramento de outros procedimentos considerados menos invasivos no corpopaciente, percebe-se ao mesmo tempo um declínio, assim como um certo desestímulo, para a utilização desse tipo de monitorização. Ou seja, entra em cena, no discurso tecnobiomédico, a relação entre os procedimentos invasivos e os procedimentos não-invasivos. É importante observar que invasivo, neste exemplo do cateter de Swan-Ganz, está sendo entendido como algo que é inserido no interior do corpopaciente e que permanece em seu interior. Ou seja, é estabelecido um contato profundo e contínuo com o interior desse corpo-paciente. Não-invasivo, por outro lado, é entendido como algo que entra em contato com o corpo-paciente, mas esse contato é feito ora pela superfície da pele ou com o que é nomeado como parte externa do corpo do paciente, ora com a sua parte interna. Isto é, alguns procedimentos ditos nãoinvasivos também são inseridos internamente no paciente. O que muda em relação aos invasivos é o fato de não permanecerem, ali, continuamente. Independentemente disso, tanto a monitorização invasiva quanto a não-invasiva propõemse a visualizar o interior do indivíduo. Mais uma vez, a opacidade corporal, que impediria que víssemos as estruturas que compõem os nossos corpos, deixa de ser problema. Através dos procedimentos invasivo e não-invasivo, podemos pensar que as relações entre dentro/fora ou, mais explicitamente, entre a superfície e o interior articulam-se de maneira combinada: o interior é superficializado, e a superfície, interiorizada.

Ainda nessa direção, é pertinente apontar para o aspecto de que, desde 1960, com a união entre computadores e a tecnologia médica do Raio $X$, tem sido possível a obtenção de imagens das estruturas internas e das funções do corpo humano e que estas, somadas à habilidade do profissional, contribuem para a elaboração de diagnósticos de determinadas doenças. Sendo assim, a pele não se constitui mais numa barreira para a técnica visualizar o interior do corpo, e a tecnobiomedicina transforma aquilo que é invisível "a olho nu" em dado visível, atribuindo-lhe um status de realidade ${ }^{(16)}$. Por conseguinte, as enfermeiras intensivistas, também, tornam-se especialistas em exteriorizar o que ainda é nomeado e reconhecido como sendo o interior do corpo, através de todo um aparato de monitoramento.

Em suma, polaridades como o profundo e o superficial, o dentro e o fora, o interior e o exterior e o subjetivo e o objetivo são distinções que a/o profissional enfermeira/o, ao desenvolver seu trabalho plugando-se com a máquina na UTI, torna problemáticas e suscetíveis de serem desconstruídas. Desse modo, o caráter naturalizado do que pode ser considerado como profundo, dentro, interior e subjetivo nessa experiência de visão é questionado e deslocado, justamente, pela polaridade considerada antagônica: superficial, fora, exterior e objetivo.

O corpo não cessa de ser redescoberto ao mesmo tempo em que nunca é totalmente revelado(7). Essa assertiva de Sant'anna remonta à questão de que esse corpo não existe como essência, que não é algo que esteja simplesmente aí à espera de ser revelado, descoberto ou respeitado. E, nessa direção, podemos dizer que "aquilo que se vê depende de onde nos situamos e quando. O que pretendemos, pela visão, é função da nossa posição no tempo e no espaço"(16:1). Normalmente, os usuários das tecnologias geradoras de imagens não constumam questionar a objetividade, neutralidade e veracidade dessas imagens.

As imagens produzidas pelos artefatos tecnológicos são, em geral, tidas como evidências médicas, objetivas e confiáveis, ou seja, assume-se que a interpretação dessas imagens é não-problemática, que ‘aquilo que se vê é o que é na realidade'(16:1)

Assim, entre esses usuários, o que passa a importar são as traduções que objetivam esclarecer os modos de conhecer o corpo através das tecnologias de visualização. A partir desse pressuposto, em meio a uma gama possível de coisas que aí importam, desejamos sinalizar, através de duas indagações, outro viés dessa discussão: em um ambiente permeado pela tecnobiomedicina, o que conta como verdade e como essa verdade é contada? A quem se destinam os guias e os manuais de orientação acerca dos equipamentos disponibilizados pela indústria da tecnobiomedicina?

Este guia destina-se aos Engenheiros Biomédicos do hospital ou aos Especialistas Clínicos e de Manutenção da Hewlett-Packard que têm que executar os procedimentos de configuração do HP Viridia M3/M4. Destina-se também às Enfermeiras e Clínicos que necessitam alterar a configuração do equipamento de acordo com as suas necessidades ${ }^{(17: 1)}$.

Contém todas as informações gerais acerca do monitor e é um bom ponto de partida para novos usuários, pois proporciona urna introdução ao sistema e ao seu modo de funcionamento, mostra como começar a utilizá-lo e fornece informações passo a passo sobre o uso de teclas na utilização do monitor (12:5).

Equipamento projetado e construído para satisfazer os mais rígidos critérios de qualidade e precisão. Emprega a mais recente tecnologia em arquitetura computadorizada dedicada, visando a maior rapidez e eficiência no diagnóstico e acompanhamento dos clientes monitorizados. É um aparelho modular, podendo ser fornecido em diversas configurações distintas, conforme as necessidades. O aparelho é fabricado de modo a possibilitar ao usuário a ampliação, a posteriori, para qualquer configuração, dentro das seguintes opções: 
ECG; pressão não-invasiva; temperatura; débito cardíaco; freqüência respiratória; oximetria de pulso. É um aparelho auto-explicativo, possuindo uma tela de auxílio para o usuário, mostrando o significado das principais teclas usadas na operação ${ }^{(9: 325-6)}$.

As duas primeiras citações indicam que um guia do usuário deve ser capaz de traduzir para usuários/as, explicitamente indicados/as, os modos de utilização adequada dos mais diversos equipamentos. A terceira citação anuncia a mesma coisa, mas de outro modo. Ou seja, tal citação sinaliza que um equipamento moderno deve ser auto-explicativo para o/a usuário/a e, nesse caso, à medida em que o/a usuário/a utiliza essa máquina, ele/ela estará interagindo com ela. No entanto, balizadas em algumas das concepções que estudamos ${ }^{(18)}$, entendemos que o conhecimento teóricotécnico-científico, se aplicado, entre outros campos possíveis atualmente, na tecnobiomedicina, implica uma mudança radical na atuação, também, de quem projeta os equipamentos utilizados na terapia intensiva. Nessa direção, mesmo que estejamos, aqui, tratando dos/as usuários/as desses equipamentos no contexto da UTI, e mesmo que centralizemos nossa discussão na questão da tradução adequada aos/às usuários/as que aplicarão esses inventos em outros seres humanos e, em função disso, estejamos nos referindo a nós, técnicos/as usuários/as desses equipamentos, não podemos abster-nos de articular esse tipo de tradução a um contexto sociocultural mais amplo. Latour faz uma utilização prática do conceito de tradução quando discute sua teoria de rede sociotécnica. Traduzir, para Latour, significa

atribuir a um elemento de uma rede um papel a ser representado por ele; significa emprestar-lhe uma identidade, prática que é realizada por todos os elementos de uma rede num movimento mútuo e contínuo, a partir dos desejos, expectativas ou interesses de cada um dos 'tradutores ${ }^{(20: 54)}$.

Mas, para que as traduções passem a ser consideradas corretas e, portanto, sejam tomadas como indiscutíveis, uma entidade a quem se atribui um papel dado não deve contradizer seu tradutor ou porta-voz.

Uma tradução bem-sucedida "depende assim da capacidade de negociação dos atores, na medida em que definir papéis supõe convencer os outros a desempenhá-los" ${ }^{(19)}$. Deste modo, nessa rede sociotécnica, os engenheiros seriam os tradutores dos comportamentos dos/das futuros/as usuários/ as - enfermeiras, médicos/as e engenheiros/as biomédicos hospitalares - e dos artefatos - equipamentos tecnobiomédicos - que projetam.

O senso de visão dos pesquisadores e pesquisadoras deveria ser inserido também como tema para todos os argumentos tecnológicos. Podemos, então, afirmar que, na terapia intensiva, o status do olhar é dispersado através dos instrumentos e dos/as profissionais que olham, todos instrumentos e profissionais - celebrados pelas suas habilidades de avivar o corpo dentro de um campo de alcance da visibilidade. Consideramos, pois, que estamos lidando, novamente, com um processo de reorganização desse olhar, uma vez que o sentido do monitoramento acaba por refletir um novo status do corpo como um sistema móvel de reorganização de novos tipos de corpos. Deste modo, o scope do monitor distancia o observador de uma visão de corpo que é vista em geral fora desse ambiente permeado por sistema de monitoramento. Sendo assim, o sistema de scopia, tal como abordado aqui, diz de uma imagem ampliada das estruturas internas e externas do corpo; dos espaços corporais que são visualizados e dos espaços corporais que não são visualizados; e de uma técnica específica para olhar a partir desses instrumentos tecnológicos de visualização ${ }^{(20)}$.

É interessante observar com a autora ${ }^{(20)}$ que é comumente sustentado o aspecto de que o sistema de scopia aumenta a extensão da visão de um observador ou observadora, permitindo a percepção do oculto e das imperceptíveis estruturas do corpo. Essa concepção de um sistema de scopia como aprimoramento do olhar de quem olha, de certo modo, legitima a idéia de que existem algumas verdades que são inquestionáveis ${ }^{(20)}$. Em contrapartida, a partir da perspectiva de análise adotada nesta investigação, entende-se o sistema de scopia projetado em laboratório como um singular ponto de vista que adota técnicas para conseguir olhar através da imagem da máquina, diferentemente da imagem do olho do observador. O focus da máquina, o focus do/a observador/a e o focus do/a observador/a através do focus da máquina são modos (convenções) privilegiados de novas configurações de corpo, vida e subjetividade. Para além disso, normalmente é "silenciado" o fato de que todo esse sistema óptico constitui-se em um aparato de normas culturais e de poder acerca dos corpos e das subjetividades. As posições do/a técnico/a (e nós aqui reutilizamos essa noção para a enfermeira intensivista e para a própria máquina), do/a paciente e do objeto (no caso o sistema de scopia) como posições instáveis e sujeitas, muitas vezes, ao desaparecimento(20).

\section{3 À guisa de conclusão}

Poderíamos, aqui, nos estender através de um interminável número de trechos extraídos dos manuais para problematizar diferentes modos pelos quais a máquina escreve o corpo humano nas UTIs, constituindo-o, portanto, como outro(s) tipo(s) de corpo(s). Nesse sentido, na terapia intensiva, há a possibilidade de a profissional olhar o corpo do/a paciente através da máquina que o constitui a partir de uma multiplicidade de imagens de corpos doentes. Assim, ao explorarmos processos de textualização do corpo pela imagem, procuramos sempre reforçar o aspecto de que o corpo é o que dizemos dele. Ele deixa, pois, de constituir uma presença original. A máquina é uma escrita, um pensamento e um texto. O corpo, olhado e decodidificado pela máquina, e na conexão do humano com a máquina, também é uma escrita, um pensamento e um texto. Radicalizando: tudo é escrita; a doença é escrita; o corpo humano é escrita. Se são escrita, doença e corpo humano opõem-se à presença física e podem ser retirados e extraídos de seu contexto. Deste modo, nenhum contexto esgota aquilo que ele contém. Nenhum contexto pode encerrar-se em si mesmo.

Então, na medida em que nos vemos imbricadas nessa rede de relações, responderíamos que o que conta como verdade e como essa verdade é contada em um ambiente permeado pela tecnobiomedicina envolve compreender as relações entre a indústria e a ciência e seus desdobramentos, em toda uma gama de métodos que resultam na dinâmica da aplicação dos mais diversos equipamentos ${ }^{(21)}$. Nesse sentido, a tradução, a informação gerada a partir dessa tradução e a tecnologia são mutuamente constitutivas e estão, em última análise, intrinsecamente articuladas. Em outras palavras, não se deveria pensar de forma separada e estanque em equipamentos disponibilizados pela indústria da tecnobiomedina, em enfermeiras intensivistas cuidando de seus/suas pacientes na UTI e na informação gerada a partir desses equipamentos e suas implicações no tratar/cuidar dos/ das pacientes; seria necessário e pertinente, isto sim, visualizar e problematizar toda essa rede de relações como instâncias de produção e disseminação de sentidos sobre o corpo, a vida e o cuidar em enfermagem.

\section{Referências}

1. Haraway DJ. Simians, ciborgs and women: the reinvention of nature. London: FAB; 1991. 287 p. 
2. Haraway DJ. Modest_Witness@Second_Millennium.FemaleMan@ Meets OncoMouse ${ }^{\overline{T M}}$ : feminism and technoscience. New York: Routlēge; c1997. 361 p. il.

3. Haraway DJ. Manifesto ciborgue: ciência, tecnologia e feminismosocialista no final do século XX. In: Silva TT, organizador. Antropologia do ciborgue: as vertigens do pós-humano. Belo Horizonte (MG): Autêntica; 2000. 142 p. p. 37-129.

4. Silva TT. O currículo como fetiche. Belo Horizonte (MG): Autêntica; 1999. $117 \mathrm{p}$.

5. Foucault, M. O nascimento da clínica. $4^{\mathrm{a}}$ ed. Rio de Janeiro: Forense; 1994. $241 \mathrm{p}$

6. Silva AM. Corpo, ciência e mercado: reflexões acerca da gestação de um novo arquétipo da felicidade. Campinas (SP): Autores Associados; 2001. 144 p. (Educação Física e esportes).

7. Sant'Anna DB. Corpos de passagem: ensaios sobre a subjetividade contemporânea. São Paulo: Estação Liberdade; [2001]. 127 p.

8. Zimerman LI, Chodosz ELK. Arritmias cardíacas de alto risco. In Menna Barreto SS, Vieira, SRR, Pinheiro CTS, organizadores. Rotinas em terapia intensiva. $3^{\mathrm{a}}$ ed. Porto Alegre (RS): ARTMED; c2001. 694 p. il. p. 86-91.

9. Yako IYO. Manual dos procedimentos invasivos realizados no CTI: atuação das enfermeiras. Rio de Janeiro: MEDSI, 2000. 462 p. il.

10.Baxter E. Swanganz. Los Angeles (CA): Edwards Critical-Care Division; 1997. 4 p.

11.Ribeiro SF. Monitorização hemodinâmica não-invasiva. In: Cintra EA Nishide VM, Nunes WA, organizadores. Assistência de enfermagem ao paciente crítico. São Paulo: Atheneu; 2000. 671 p. il. p. 107-21.

12. Hewlett Packard. HP Virídia: guia do usuário. 3a ed. Böblingen; 1999. $404 \mathrm{p}$.

13.Pinheiro CTS, Both MA. Monitorização cardiorrespiratória. In: Menna
Barreto SS, organizador. Rotinas em terapia intensiva. Porto Alegre (RS): Artes Médicas; 1990. 353 p. p. 49-56. (Série biomédica).

14.Both MA. Inserção de cateter de Swanganz. In: Menna Barreto SS, organizador. Rotinas em terapia intensiva. $2^{\mathrm{a}}$ ed. Porto Alegre (RS): Artes Médicas; 1993. 373 p. il. p. 307-8.

15.Azmus AD, Maratia L. Monitorização hemodinâmica. In: Menna Barreto SS, Vieira SRR, Pinheiro CTS, organizadores. Rotinas em terapia intensiva. $3^{\mathrm{a}}$ ed. Porto Alegre (RS): ARTMED; c2001. 694 p. il. p. 4752.

16. Monteiro RH. Videografias do coração: um estudo etnográfico do cateterismo cardíaco [dissertação de Mestrado]. Campinas (SP): Universidade Estadual de Campinas; 2001. 149 f. il.

17. Hewlett Packard. HP Virídia M3/M4: guia do usuário para configuração. Böblingen; 1999. 20 p.

18.Latour B. Jamais fomos modernos. São Paulo: Ed. 34; 1994. 149 p. il. (Coleção trans).

19.Benakouche T. Duas culturas, três culturas... ou redes? Dilemas da análise social da técnica. In: Baumgarten M. A era do conhecimento: matrix ou Ágora? Porto Alegre (RS): Editora da UFRGS; 2001. 263 p. p.45-59.

20.Cartwright L. Screening the body: tracing medicine's visual culture. $2^{\mathrm{a}}$ print. Minneapolis (MN): University of Minnesota Press, 1997. 199 p.

21.Lenoir T. A virtualidade na ciência: o caso das cirurgias virtuais. Episteme: Filosofia e História das Ciências em Revista, Porto Alegre (RS) $1997 ; 2(4): 73-101$.

Data de recebimento: 20/02/2003

Data de aprovação: 26/06/2003 